\title{
Retinal Functional Changes Measured by Microperimetry after Intravitreal Ranibizumab Injection and Sulfotanshinone Sodium Injection for Macular Edema Secondary to Retinal Vein Occlusion
}

\author{
Bingwen Lu, Xingwei Wu \\ Ophthalmology Department, Shanghai First People's Hospital, Shanghai, China \\ Email: 704487389@qq.com
}

Received 27 August 2015; accepted 21 September 2015; published 24 September 2015

Copyright (C) 2015 by authors and Scientific Research Publishing Inc.

This work is licensed under the Creative Commons Attribution International License (CC BY). http://creativecommons.org/licenses/by/4.0/

\section{Abstract}

Objectives: To study the visual field changes after intravitreal ranibizumab (IVR) injection and sulfotanshinone sodium (SS) injection for macular edema (ME) secondary to retinal vein occlusion (RVO), and discuss the value of microperimetry as a routine diagnostic test in the follow-up of RVO patients. Methods: This was a retrospective, interventional, case-series study. Twelve eyes of 12 RVO patients, including 6 eyes with central RVO (CRVO) and 6 eyes with branch RVO (BRVO) were included. The eyes were treated with IVR $(0.5 \mathrm{mg})$ injections and SS injections $(20 \mathrm{mg}$ per day, one week consecutively in one month). The outcomes measured included best corrected visual acuity (BCVA), central retinal thickness (CRT), mean defect (MD), pattern standard deviation (PSD), macular light sensitivity of the central 16 points in CRVO group and the central 8 points in BRVO group before and after the treatment. Statistical analyses were then performed on the main outcome measures. Results: An improvement of BCVA was found in all patients after treatment with significant difference $(t=7.74, p<0.01)$. CRT improved from $(700.3 \pm 184.9) \mu \mathrm{m}$ before treatment to $(235.3 \pm 36.5 \mu \mathrm{m})$ after treatment $(\mathrm{t}=\mathbf{8 . 2 4}, p<0.01)$. As for the results of visual field, MD improved significantly $(t=5.83, p<0.01)$, whereas the changes of PSD showed no significant importance $(\mathrm{t}=2.17, p>0.05)$. All RVO patients had their macular light sensitivity of the involved part improved significantly $(t=5.03, p<0.01)$. Both the macular light sensitivity of the central 16 points in the CRVO group and the macular light sensitivity of the central 8 points in the BRVO group improved with statistical importance $(t=3.78, p<0.05 ; t=5.38, p<0.01)$. The Pearson's correlation was calculated among BCVA, MD, macular light sensitivity and CRT. No obvious significance was found between CRT and BCVA outcomes, whereas MD and mean macular light sensitivity outcomes were closely related to BCVA results in the BRVO group and the latter showed a 
more intimate correlation. No similar correlation was found in RVO and CRVO group. Conclusion: IVR injection and SS injection together could effectively improve the therapeutic effect in RVO patients with ME. Microperimetry could be used as a routine diagnostic test and a possible valuable tool in the follow-up of patients with RVO, especially in BRVO.

\section{Keywords}

\section{Intravitreal Ranibizumab Injection, Sulfotanshinone Sodium Injection, Retinal Vein Occlusion, Macular Edema, Microperimetry, Visual Field Changes}

\section{Introduction}

Retinal vein occlusion (RVO) is estimated to be the second most common cause of retinal vascular disease [1]. Macular edema (ME) is a frequent cause of visual acuity loss [2]. Since the Branch Vein Occlusion Study Group reported the efficacy of grid laser photocoagulation, it has been recognized as the standard treatment for ME resulting from branch RVO (BRVO) [3]. But recently, an increasing number of reports have shown the efficacy of new methods on ME resulting from RVO, such as intravitreal injections of triamcinolone acetonide, bevacizumab, or ranibizumab [4]-[6]. Our previous study has also demonstrated that sulfotanshinone sodium (SS) injection could effectively improve the therapeutic effect in patients with non-ischemic RVO [7].

In order to specify conditions for re-treatment, a concise evaluation of the macular function is needed. To date, initial visual acuity (VA) is the most reliable prognostic factor of visual prognosis [3] and quantitative measurement of central retinal thickness (CRT) using optical coherence tomography (OCT) is generally used to evaluate both the severity of the ME and the effect of the treatment [6]. However, the assessment of CRT by OCT predominantly supplies information of the anatomical rather than the functional result. Moreover, OCT measurements may detect a significant edema reduction while the visual acuity fails [8]. Consequently, microperimetry has been reported recently to be a valuable additional diagnostic measure for macular diseases [8].

The purpose of the present study is to analyze the sensitivity and qualification of MP as a possible routine diagnostic test for RVO.

\section{Materials and Methods}

\subsection{Research Objects}

This was a retrospective, interventional, case-series study conducted at Ophthalmology Department of Shanghai First People's Hospital. Twelve eyes of 12 RVO patients, including 6 eyes with central RVO (CRVO) and 6 eyes with BRVO were included. All patients were examined by complete ophthalmologic examination. Patients included should meet the eligibility criteria as follows: 1) age of at least 18 years old with RVO,; 2) color fundus photography featured thin retinal artery, dilated vein, posterior pole retinal edema and hemorrhage; 3) fundus fluorescence angiography (FFA) featured delayed arterial filling, delayed retinal arterial branches filling, and capillary non-perfusion (NP); 4) macular edema. Patients were excluded from the study if they had undergone any other treatment for RVO within 3 months, such as laser therapy or intravitreal injections. Patients with coexisting ocular disease (glaucoma, diabetic retinopathy, or senile cataract that resulted in poor quality of OCT images) in either eye were also excluded from the present study. This study was approved by the Institusional Review Board at Shanghai Jiao Tong University Graduate School of Medicine. Written informed consent was obtained from each patient after provision of sufficient information about the procedures.

\subsection{Experiment Medicine}

The enrolled RVO patients were treated with intravitreal ranibizumab (IVR) injection as well as SS injections (20 mg per day, one week consecutively in one month). Ranibizumab ( $0.5 \mathrm{mg}$ ) (Lucentis, Genentech Inc.) was injected through the pars plana $3.5 \mathrm{~mm}$ to $4.0 \mathrm{~mm}$ posterior to the surgical limbus using a 30-gauge needle. SS injection ( $5 \mathrm{mg} / \mathrm{ml}$ ) (batch number: H120921) manufactured by the First Biochemical Pharmaceutical Co. Ltd., Shanghai, China, is approved by State Food and Drug Administration of China. SS injection is given diluted at 
the point of treatment in $250 \mathrm{~mL}$ 5\% glucose injection for intravenous administration. In addition to the treatment medicines, usages of any other traditional Chinese medicine or modern western medicine that affects blood circulation during the 6 months follow-up were prohibited.

\subsection{Experiment Methods}

A detailed history was taken to ascertain each patient's demographics and chief complaints.

One day before and 1 month after the treatment, changes in best corrected visual acuity (BCVA), CRT, mean defect (MD), pattern standard deviation (PSD) as well as macular light sensitivity of the central 16 points in CRVO group and the central 8 points in BRVO group were analyzed. ETDRS chart was used to measure BCVA. CRT was measured by OCT (Zeiss, Germany). MD, PSD and macular light sensitivity were measured by Humphrey 720 auto-perimetry (30 - 2).

\subsection{Statistical Analysis}

Test results were represented by $\mathrm{x} \pm \mathrm{s}$ using the SPSS 18.0 software. Changes in BCVA, CRT, MD, PSD and macular light sensitivity measurements from baseline were assessed with paired $t$ test. The Pearson's correlation was calculated among BCVA, MD, macular light sensitivity and CRT. $P$ values less than 0.05 were considered statistically significant in this study.

\section{Results}

\subsection{Patient Demographics and Baseline Characteristics}

A total of 12 eyes of 12 RVO patients (2 men and 10 women) were included in the study, with 6 CRVO patients and 6 BRVO patients. The mean age of the study population was $61.4 \pm 3.7$ years (range $57-69$ years). At the initial visit, mean BCVA measured by ETDRS criteria was $47 \pm 24$ letters. All affected eyes had ME with cystoids spaces at the fovea, in which mean CRT was $700.3 \pm 184.9 \mu \mathrm{m}$. See Table 1 for detailed information.

\subsection{Visual Acuity, CRT and Visual Field before and after Treatment}

RVO patients had a mean BCVA of $47 \pm 24$ letters before treatment. After IVR injection as well as SS injections, mean BCVA improved to $70 \pm 16$ letters, which was of significant difference $(t=7.73, p<0.01)$. Visual acuity was improved both in CRVO group and BRVO group.

The mean CRT of RVO patients before and after treatment were $(700.3 \pm 184.9) \mu \mathrm{m}$ and $(235.3 \pm 36.5) \mu \mathrm{m}$, respectively. The changes in CRT from baseline were statistically significant $(t=8.24, p<0.01)$. CRT results were greatly reduced both in CRVO group and BRVO group.

As for the results of visual field, the changes in mean MD before and after treatment were statistically significant $(\mathrm{t}=8.24, p<0.01)$, which improved from $(-7.1 \pm 2.6) \mathrm{dB}$ to $(-5.5 \pm 1.9) \mathrm{dB}$. While the changes in mean PSD had no significant difference statistically $(\mathrm{t}=2.174, p>0.01)$, changing from $(6.2 \pm 3.5) \mathrm{dB}$ before treatment to $(5.2 \pm 3.2) \mathrm{dB}$ after treatment.

All RVO patients had their macular light sensitivity of the involved part changed from $(21.8 \pm 1.5) \mathrm{dB}$ to $(24.4 \pm 1.1) \mathrm{dB}(\mathrm{t}=5.03, p<0.01)$.

Table 1. General information of the 12 RVO patients at the initial visit.

\begin{tabular}{|c|c|c|c|}
\hline & RVO & CRVO & BRVO \\
\hline Number of patients & 12 & 6 & 6 \\
\hline Mean age & $61.4 \pm 3.7$ (57 - 69 years old $)$ & $63.4 \pm 3.3(61-69$ years old $)$ & $63.4 \pm 3.3(57-65$ years old $)$ \\
\hline Male & 2 & 1 & 1 \\
\hline Female & 10 & 5 & 5 \\
\hline Mean BCVA (ETDRS letters) & $47 \pm 24$ & $38 \pm 24$ & $55 \pm 22$ \\
\hline Mean CRT ( $\mu \mathrm{m})$ & $700.3 \pm 184.9$ & $741.33 \pm 209.21$ & $659.33 \pm 165.63$ \\
\hline
\end{tabular}


Macular light sensitivity of the central 16 points in the CRVO group changed from ( $25.4 \pm 1.7) \mathrm{dB}$ to $(26.8 \pm$ 1.7) $\mathrm{dB}$ with statistical difference $(\mathrm{t}=3.78, p<0.05)$.

Also, macular light sensitivity of the central 8 points in the BRVO group changed from $(18.3 \pm 4.9) \mathrm{dB}$ to $(22.0 \pm 3.9) \mathrm{dB}$ with significant difference $(\mathrm{t}=5.38, p<0.01)$.

The results of visual acuity, CRT and visual field at baseline as well as after treatment of all RVO patients are presented in Table 2.

In CRVO group, mean BCVA was $38 \pm 24$ letters and mean CRT was $(741.3 \pm 209.2) \mu \mathrm{m}$, the changes of which were both statistically significant when compared to the baseline $(\mathrm{t}=7.04, p<0.01 ; \mathrm{t}=6.43, p<0.01)$. Mean MD and mean light sensitivity of the central 16 points raised to $(-4.8 \pm 1.4) \mathrm{dB}$ and $(26.8 \pm 1.7) \mathrm{dB}$ respectively, the change of which was of statistical importance $(\mathrm{t}=4.13, p<0.01)$ while the change of mean PSD had none $(t=0.46, p>0.05)$. The results of visual acuity, CRT and visual field at baseline as well as after treatment of CRVO patients are presented in Table 3.

In BRVO group, mean BCVA was $55 \pm 22$ letters and mean CRT was $(255.83 \pm 36.88) \mu \mathrm{m}$, the changes of which were both statistically significant $(\mathrm{t}=8.09, p<0.01$; $\mathrm{t}=5.31, p<0.01)$. Mean light sensitivity of the involved central 8 points raised to $(7.0 \pm 3.3) \mathrm{dB}$ the change of which was of statistical importance $(\mathrm{t}=5.38, p<$ 0.01 ) while the change of mean MD and mean PSD before and after treatment had no such significant difference $(\mathrm{t}=3.79, p<0.05 ; \mathrm{t}=3.30, p<0.05)$. The results of visual acuity, CRT and visual field at baseline as well as after treatment of BRVO patients are presented in Table 4.

Table 2. Results of visual acuity, CRT and visual field at baseline as well as after treatment of all RVO patients.

\begin{tabular}{ccccccc}
\hline RVO & Eyes & $\begin{array}{c}\text { Mean BCVA } \\
(\text { ETDRS letters })\end{array}$ & $\begin{array}{c}\text { Mean CRT } \\
(\mu \mathrm{m})\end{array}$ & $\begin{array}{c}\text { Mean MD } \\
(\mathrm{dB})\end{array}$ & $\begin{array}{c}\text { Mean PSD } \\
(\mathrm{dB})\end{array}$ & $\begin{array}{c}\text { Mean light sensitivity } \\
\text { of the affected area }(\mathrm{dB})\end{array}$ \\
\hline $\begin{array}{c}\text { Baseline } \\
\begin{array}{c}4 \text { weeks } \\
\text { after treatment }\end{array}\end{array}$ & 12 & $47 \pm 24$ & $700.3 \pm 184.9$ & $-7.1 \pm 2.6$ & $6.2 \pm 3.5$ & $21.8 \pm 1.5$ \\
$\mathrm{t}$ & 12 & $70 \pm 16$ & $235.3 \pm 36.5$ & $-5.5 \pm 1.9$ & $5.2 \pm 3.2$ & $24.4 \pm 1.1$ \\
$p$ & $\mathrm{t}=7.731$ & $\mathrm{t}=8.24$ & $\mathrm{t}=5.586$ & $\mathrm{t}=2.174$ & $\mathrm{t}=5.029$ \\
& $p<0.01$ & $p<0.01$ & $p<0.01$ & $p=0.052$ & $p<0.01$
\end{tabular}

(Paired t test).

Table 3. Results of visual acuity, CRT and visual field at baseline as well as after treatment of CRVO patients.

\begin{tabular}{ccccccc}
\hline CRVO & Eyes & $\begin{array}{c}\text { Mean BCVA } \\
(\text { ETDRS letters })\end{array}$ & $\begin{array}{c}\text { Mean CRT } \\
(\mu \mathrm{m})\end{array}$ & $\begin{array}{c}\text { Mean MD } \\
(\mathrm{dB})\end{array}$ & $\begin{array}{c}\text { Mean PSD } \\
(\mathrm{dB})\end{array}$ & $\begin{array}{c}\text { Mean light sensitivity } \\
\text { of the central 16 points }(\mathrm{dB})\end{array}$ \\
\hline $\begin{array}{c}\text { Baseline } \\
\begin{array}{c}4 \text { weeks } \\
\text { ffter treatment }\end{array}\end{array}$ & 6 & $38 \pm 24$ & $741.3 \pm 209.2$ & $-6.2 \pm 2.1$ & $3.7 \pm 1.6$ & $25.4 \pm 1.7$ \\
$\mathrm{t}$ & $60 \pm 22$ & $214.7 \pm 23.5$ & $-4.8 \pm 1.4$ & $3.4 \pm 2.0$ & $26.8 \pm 1.7$ \\
$p$ & $\mathrm{t}=7.04$ & $\mathrm{t}=6.43$ & $\mathrm{t}=4.13$ & $\mathrm{t}=0.46$ & $p<0.01$ \\
& $p<0.01$ & $p<0.01$ & $p<0.01$ & $p>0.05$ & $\mathrm{t}$ \\
\hline
\end{tabular}

Table 4. Results of visual acuity, CRT and visual field at baseline as well as after treatment of BRVO patients.

\begin{tabular}{ccccccc}
\hline BRVO & Eyes & $\begin{array}{c}\text { Mean BCVA } \\
(\text { ETDRS letters })\end{array}$ & $\begin{array}{c}\text { Mean CRT } \\
(\mu \mathrm{m})\end{array}$ & $\begin{array}{c}\text { Mean MD } \\
(\mathrm{dB})\end{array}$ & $\begin{array}{c}\text { Mean PSD } \\
(\mathrm{dB})\end{array}$ & $\begin{array}{c}\text { Mean light sensitivity of the } \\
\text { involved central 8 points }(\mathrm{dB})\end{array}$ \\
\hline $\begin{array}{c}\text { Baseline } \\
\begin{array}{c}4 \text { weeks } \\
\text { after treatment }\end{array}\end{array}$ & 6 & $55 \pm 22$ & $659.33 \pm 165.63$ & $-8.00 \pm 2.90$ & $8.70 \pm 3.10$ & $18.30 \pm 4.90$ \\
$\mathrm{t}$ & 6 & $70 \pm 16$ & $255.83 \pm 36.88$ & $-6.20 \pm 2.30$ & $7.00 \pm 3.30$ & $22.00 \pm 3.90$ \\
$p$ & $\mathrm{t}=8.09$ & $\mathrm{t}=5.31$ & $\mathrm{t}=3.79$ & $\mathrm{t}=3.30$ & $\mathrm{t}=5.38$ \\
$p<0.01$ & $p<0.01$ & $p<0.05$ & $p<0.05$ & $p<0.01$ \\
\hline
\end{tabular}




\subsection{The Correlation among BCVA, CRT and Visual Field Results}

The Pearson's correlation was calculated among BCVA, MD, macular light sensitivity and CRT. No obvious significance was found between CRT before treatment and BCVA results $(\mathrm{r}=-0.549,-0.471,-0.412 ; p=0.065$, 0.346, 0.417), and none either between CRT after treatment and BCVA results ( $\mathrm{r}=-0.524,-0.145,-0.464 ; p=$ $0.080,0.784,0.354)$. Whereas MD results before and after treatment were closely related to BCVA results in the BRVO group ( $\mathrm{r}=0.821,0.971 ; p=0.016,0.007)$ and results of macular light sensitivity before and after treatment showed a more intimate correlation $(\mathrm{r}=0.971,0.928 ; p=0.007,0.009)$. No similar correlation was found in RVO and CRVO group.

\section{Discussion}

RVO is the second most common retinal vascular disease after diabetic retinopathy, with central CRVO and BRVO being the two distinct types of RVO, classified according to the site of occlusion [1]. ME is one of its most vision-threatening complications and a wide range of treatments has been explored [2]. During the last decade, intravitreal injections of triamcinolone acetonide, bevacizumab, or ranibizumab were evolved as new major treatment modality [4]-[6]. We have also proved that SS injection could effectively improve the therapeutic effect in patients with non-ischemic RVO [7].

In order to observe the therapeutic effect of the treatment on RVO patients and specify conditions for retreatment in their follow-up, evaluation of the macular function is of paramount meaning. VA is the most reliable prognostic factor of visual prognosis which has been used all along [3]. Since the last decade, quantitative measurement of CRT has also been widely used to evaluate both the severity of ME and the effect of treatment [6]. However, the CRT outcome measured by OCT may be not enough for it mainly supplied information of the anatomical rather than the functional result. Many researchers have observed the fact that visual acuity did not improve even though the OCT measurements showed a significant edema reduction [8]. Consequently, clinical measures that reflect macular function could be useful in the evaluation and follow-up of the disease [9]. Rohrschneider et al. in 2008 claimed microperimetry to be a valuable additional diagnostic for macular disease for it not only analyzed the function of a few central degrees, but also of the entire macula and it was able to detect paracentral scotoma [8]. Our present study aims to analyze the sensitivity and qualification of microperimetry as a possible routine diagnostic test for RVO.

Here, we observed that BCVA and CRT outcomes were significantly improved in all patients after treatment $(\mathrm{t}=7.74, p<0.01 ; \mathrm{t}=8.24, p<0.01)$, demonstrating that IVR injection and SS injection together could effectively improve the therapeutic effect in RVO patients with ME. MD outcomes was also significantly improved in all patients $(\mathrm{t}=5.83, p<0.01)$, whereas PSD only improved from $(6.2 \pm 3.5) \mathrm{dB}$ to $(5.2 \pm 3.2) \mathrm{dB}$, which was of no significant importance ( $\mathrm{t}=2.17, p>0.05)$. The change of macular light sensitivity of all RVO patients was of significant difference $(\mathrm{t}=5.03, p<0.01)$, with that of the central 16 points in CRVO group changing from $(25.4 \pm 1.7) \mathrm{dB}$ to $(26.8 \pm 1.7) \mathrm{dB}(\mathrm{t}=3.78, p<0.05)$, and that of the central 8 points in BRVO group changing from $(18.3 \pm 4.9) \mathrm{dB}$ to $(22.0 \pm 3.9) \mathrm{dB}(\mathrm{t}=5.38, p<0.01)$.

The Pearson's correlation conducted demonstrated close correlation between MD and mean macular light sensitivity with BCVA results in BRVO group, with the latter being closer, while no similar correlation was found in RVO and CRVO group.

This prospective study had a number of potential limitations. The sample size was small, and the follow-up period was short. Considering the strength of the evidence, more rigorously designed trials are required for assessing the clinical application of microperimetry as a routine diagnostic test and a possible valuable tool in the follow-up of RVO patients, especially in BRVO.

\section{Conclusion}

In summary, IVR injection and SS injection together could effectively improve the therapeutic effect in RVO patients with ME. Microperimetry could be used as a routine diagnostic test and a possible valuable tool in the follow-up of patients with RVO, especially in BRVO.

\section{Acknowledgements}

This work was supported by a grant from Shanghai First People’s Hospital. The authors were grateful to Professor Wu from Shanghai First People's Hospital for final edict of this manuscript. 


\section{References}

[1] Querques, G., Triolo, G., Casalino, G., García-Arumí, J., Badal, J., Zapata, M., Boixadera, A., Castillo, V.M. and Bandello, F. (2013) Retinal Venous Occlusions: Diagnosis and Choice of Treatments. Ophthalmic Research, 49, 215-222. http://dx.doi.org/10.1159/000346734

[2] Hahn, P. and Fekrat, S. (2012) Best Practices for Treatment of Retinal Vein Occlusion. Current Opinion in Ophthalmology, 23, 175-181. http://dx.doi.org/10.1097/ICU.0b013e3283524148

[3] Rogers, S., McIntosh, R.L., Cheung, N., Lim, L., Wang, J.J., Mitchell, P., et al. (2010) The Prevalence of Retinal Vein Occlusion: Pooled Data from Population Studies from the United States, Europe, Asia, and Australia. Ophthalmology, 117, 313-319. http://dx.doi.org/10.1016/j.ophtha.2009.07.017

[4] Gregori, N.Z., Rosenfeld, P.J., Puliafito, C.A., Flynn Jr., H.W., Lee, J.E., Mavrofrides, E.C., et al. (2006) One-Year Safety and Efficacy of Intravitreal Triamcinolone Acetonide for the Management of Macular Edema Secondary to Central Vein Occlusion. Retina, 26, 889-895. http://dx.doi.org/10.1097/01.iae.0000237111.82357.30

[5] Prager, F., Michels, S., Kriechbaum, K., Georgopoulos, M., Funk, M., Geitzenauer, W., et al. (2009) Intravitreal Bevacizumab $\left(\right.$ Avastin $^{\circledR}$ ) for Macular Oedema Secondary to Retinal Vein Occlusion: 12-Month Results of Prospective Clinical Trial. British Journal of Ophthalmology, 93, 452-456. http://dx.doi.org/10.1136/bjo.2008.141085

[6] Brown, D.M., Campochiaro, P.A., Bhisitkul, R.B., Ho, A.C., Gray, S., Saroj, N., et al. (2011) Sustained Benefits from Ranibizumab for Macular Edema Following Branch Retinal Vein Occlusion: 12-Month Outcomes of a Phase III Study. Ophthalmology, 118, 1594-1602. http://dx.doi.org/10.1016/j.ophtha.2011.02.022

[7] Lu, B.W. and Wu, X.W. (2015) Clinical Study of Sulfotanshinone Sodium Injection in Treating Non-Ischemic Retinal Vein Occlusion. Chinese Medicine, 6, 83-89. http://dx.doi.org/10.4236/cm.2015.62009

[8] Rohrschneider, K., Bueltmann, S. and Springer, C. (2008) Use of Fundus Perimetry (Microperimetry) to Quantify Macular Sensitivity. Progress in Retinal and Eye Research, 27, 536-548. http://dx.doi.org/10.1016/j.preteyeres.2008.07.003

[9] Winterhalter, S., Lux, A., Maier, A.K., Scholz, C., Heußen, F.M.A., Huber, K.K. and Joussen, A.M. (2012) Microperimetry as a Routine Diagnostic Test in the Follow-Up of Retinal Vein Occlusion? Graefe's Archive for Clinical and Experimental Ophthalmology, 250, 175-183. http://dx.doi.org/10.1007/s00417-011-1784-8 